\title{
Gene mutation profile and risk stratification in AML1-ETO-positive acute myeloid leukemia based on next-generation sequencing
}

\author{
GUOPAN YU ${ }^{1 *}$, CHANGXIN YIN $^{1 *}$, FUQUN WU ${ }^{2}$, LING JIANG $^{1}$, ZHONGXIN ZHENG ${ }^{1}$, \\ DAN XU ${ }^{1}$, JIAHENG ZHOU ${ }^{3}$, XUEJIE JIANG ${ }^{1}$, QIFA LIU ${ }^{1}$ and FANYI MENG ${ }^{1,2}$ \\ ${ }^{1}$ Department of Hematology, Nanfang Hospital, Southern Medical University, Guangzhou, Guangdong 510515;
${ }^{2}$ Hematopathy Diagnosis and Therapy Center, Kanghua Hospital, Dongguan, Guangdong 523000;
${ }^{3}$ Department of Clinical Medicine, Southern Medical University, Guangzhou, Guangdong 510515, P.R. China
}

Received March 26, 2019; Accepted September 9, 2019

DOI: 10.3892/or.2019.7375

\begin{abstract}
Gene mutations play an important role in the development and progression of AML1-ETO-positive acute myeloid leukemia (AE-AML). Nevertheless, the gene mutation profile in this subtype of leukemia remains unclear. In addition, the clinical and prognostic effects of different mutant genes may be underestimated. In the present study, gene sequencing was conducted at diagnosis and relapse with next-generation sequencing (NGS) in 64 patients with newly diagnosed AE-AML, and 44/64 (68.8\%) patients were found to present with a median of 2 (1-10) recurrent mutations at diagnosis and $6 / 11(54.5 \%)$ cases were found to present with genetic alterations at relapse. c-KIT mutation was the most common in this cohort, with an incidence of 27/64 (42.2\%) at diagnosis, followed by ASXL1 ( $\mathrm{n}=10,15.6 \%), \operatorname{MET}(\mathrm{n}=8,12.5 \%), \operatorname{MLH1}(\mathrm{n}=6,9.4 \%)$, TET2 (n=5, 7.8\%), and FBXW7, TP53 and DNMT3A $(\mathrm{n}=5$, $7.8 \%$ ). Survival analysis showed that $c-K I T$ (exon 8,17 ) but not exon 10 adversely affected survival. In addition, $A S X L 1$ and TP53 were poor impact factors for recurrence-free survival (RFS) $(\mathrm{P}<0.05)$, and ASXL1, MET, FBXW7 and TP53 had a negative impact on overall survival $(\mathrm{OS})(\mathrm{P}<0.05)$. Multivariate analysis showed that $c$-KIT (exon 8,17 ) [RFS: hazard ratio (HR) 3.36, 95\% confidence interval (CI) 1.54-7.34, $\mathrm{P}=0.002$; OS: HR 2.84, 95\% CI 1.20-6.71, $\mathrm{P}=0.018]$ and $A S X L 1$ mutations (RFS: HR 3.13, 95\% CI 1.34-7.32, P=0.009; OS: HR 3.94, 95\% CI 1.62-9.61, $\mathrm{P}=0.003$ ) were independent adverse factors
\end{abstract}

Correspondence to: Professor Fanyi Meng, Department of Hematology, Nanfang Hospital, Southern Medical University 1838 North Guangzhou Avenue, Guangzhou, Guangdong 510515, P.R. China

E-mail: mengfu@medmail.com.cn

*Contributed equally

Key words: acute myeloid leukemia, AML1-ETO, gene mutation, next-generation sequencing for survival. Further, co-mutation of these two genes showed even worse effect on disease outcome. Collectively, additional gene mutations play critical role in AE-AML. C-KIT and ASXL1 mutations are the two most common mutations in this subtype of leukemia. $C$-KIT (exon 8,17 ) but not exon 10 , and also the $A S X L 1$ mutation poorly affect the disease outcome of this disease.

\section{Introduction}

$\mathrm{T}(8 ; 21) / A M L 1-E T O$-positive acute myeloid leukemia (abbreviated as AE-AML), accounting for 5-10\% of all cases of AML (1), is classified as a favorable leukemia subtype according to the World Health Organization (WHO) classification of AML (2). Nevertheless, numerous studies show a high incidence of extramedullary leukemia (EML) and additional cytogenetic abnormalities (ACAs). Moreover, the long term survival ranges from 28 to $70 \%$, indicating the clinical heterogeneity of this subtype of leukemia $(1,3,4)$.

In addition, gene mutations frequently occur and critically play a role in the development and progression of AE-AML. Krauth et al reported that up to $49.6 \%$ AE-AML patients present with additional gene mutations at diagnosis, and $66.7 \%$ undergo genetic alterations at the time of relapse (4). The $c-K I T$ mutation is known to be the most common molecular event in this subtype of leukemia, present in up to $12.8-48 \%$ of AE-AML patients, adversely affecting the disease outcome $(1,4)$. Several studies have shown that the AML1/ETO fusion gene is unable to singly induce leukemia, but requires additional molecular events. The $c$-KIT mutation has been proven to cooperate with the AML1-ETO fusion to induce leukemia $(3,5)$. Still there are other gene mutations, including WT1, FLT3-ITD and PDGFR mutations, that have been reported to be involved in the progression of this subtype of leukemia (6-8), further supporting an oncogenic cooperation in leukemogenesis between RUNX1-RUNX1T1 and additional molecular alterations. Therefore, detailed detection of the gene mutation profile at diagnosis and relapse could deepen the understanding of leukemia development and progression. There is a current demand for large-scale mutation screening in the clinical 
setting with a limited amount of clinical sample and reasonable turnaround time. Currently, next-generation sequencing (NGS), known as torrent Ion personal genome sequencing (PGM) platform, provides the advantages of parallel sequencing and high throughput multiplexing ability, facilitating routine and simultaneous parallel and targeted sequencing of all genes. This has been widely used in mutation profile detection and study (9-11). In our recent study (12), we designed a panel for AML gene mutation detection, which targets 67 genes covering the full coding sequence of 17 genes (Table SI) and exonic hot spot for 50 genes (Table SII). We used this panel to test 27 patients with chromosome normal (CN)-AML with NGS, and certified the result with Sanger sequencing at the same time. We found $100 \%$ sensitivity and specificity of the new platform when compared with Sanger sequencing. Meanwhile, the NGS with high-throughput had superiority in gene mutation profile detection. In this series, we used the same panel to detect the gene mutation profile at diagnosis and relapse in 64 patients with newly diagnosed AE-AML and further studied the role of different mutations on the clinical characteristics and survival. This was an observational clinical study without any interventions in regards to patient treatment, which was decided by their doctors. In this study, we enrolled 64 patients to demonstrate the common phenomenon of gene mutations at disease diagnosis and molecular alteration at leukemia relapse, and also the impact of gene mutations on clinical characteristics and disease outcome. The study aimed to further support the importance of molecular events in leukemia development and progression in AE-AML. The molecular meaning of the oncogenic pathway of AML1-ETO fusion and associated translocations are not the main point of this study, thus the study does not investigate this area in depth.

\section{Patients and methods}

Patients. Patients with newly diagnosed AE-AML, according to the WHO 2008 Classification of AML (2), and admitted to Nanfang Hospital from April 2006 to December 2013, were enrolled into this study. The characteristics of the patients are documented in Table I. All samples and clinical data were obtained upon approval of the Nanfang Hospital, Southern Medical College of Medicine Institutional Review Boards. Written informed consent was obtained from all patients and/or guardians except those admitted to Nanfang Hospital from the year 2006 to 2011, since we had obtained ethical approval with an exemption of informed consent for those patients in 2012 . According to the time that we received the ethical approval, the patients admitted to the hospital before 2012 were defined as retrospectively assigned participants, and those admitted post 2012 were defined as prospectively assigned cases.

Gene mutation sequencing. In our previous study (12), we designed a gene mutation panel for 67 AML-targeted genes covering full coding sequence of 17 genes commonly mutated in AML according to previous reports and exonic hot spot for 50 genes from the Ion AmpliSeq Cancer Hotspot Panel V2 kit (Thermo Fisher Scientific, Inc.) (detailed information is shown in Tables SI and SII). Primers for multiplex PCR of 67 target genes were designed by Ion AmpliSeq Designer (www.ampliseq. com). DNA (10 ng) (quantified by Qubit ${ }^{\mathrm{TM}}$ Fluorometer; Life
Technologies Corporation, Carlsbad, CA, USA) was used and the customized Ion AmpliSeq panel was processed using the Ion AmpliSeq Library kit 2.0 (Thermo Fisher Scientific, Inc.). Workflows related to digestion of the primers, phosphorylation of the amplicons, emulsion PCR, enrichment template-positive and sequencing on Ion 316/318 chips were performed according to the manufacturer's instructions. The raw signal data were analyzed using Torrent Suite v.4.0.2 (Life Technologies). The pipeline included signaling processing, base calling, quality score assignment, adapter trimming, read alignment to human genome GRCh37 references, mapping quality control, and coverage analysis. Several filtering steps were used to generate final variant calling.

In the present study, to further verify the results of the NGS, the detection of FLT3-ITD, $c$-KIT (exon 8 and 17), NPM1, JAK2 (V617F) and DNMT3A (R882) mutations were performed by Sanger sequencing at the same time.

MRD monitoring. AML1-ETO transcript levels, assayed by quantitative real-time polymerase chain reaction (qPCR) as described in our previous research $(13,14)$, presented an $A M L 1-E T O / A B L$ ratio, which was used to monitor minimal residual disease (MRD) after induction therapy and every consolidation chemotherapy, and then at 3-month intervals for the first 2 years of follow up, and at relapse. Major molecular remission (MMR) was defined as a $>3-\log$ reduction in AML1-ETO mRNA transcript levels when compared with the pre-treatment (15).

Treatment. All patients received the ' $3+7$ ' regimens consisting of daunorubicin (DNR) at a daily dose of $40-60 \mathrm{mg} / \mathrm{m}^{2}$ or idarubicin (IDA) at a daily dose of $8-10 \mathrm{mg} / \mathrm{m}^{2}$ or other anthracyclines for 3 days and cytarabine (Ara-C) at $100-150 \mathrm{mg} / \mathrm{m}^{2}$ per day for 7 days as induction chemotherapy for 1-2 cycles. Patient who did not achieve complete remission (CR) received salvage chemotherapy. After CR, they were mainly treated with a standard-dose Ara-C-based (SDAC-based) regimen, defined as the conventional induction regimens mentioned as before with or without 1-2 cycles of Ara-C 1-2 g/m $\mathrm{m}^{2} \mathrm{q} 12 \mathrm{~h}$ (every 12 h) x 6-8 times, before the year 2010; after that year mainly with an intermedium-dose Ara-C-based (IDAC-based) regimen, defined as receiving $\geq 3$ cycles of Ara-C $1-2 \mathrm{~g} / \mathrm{m}^{2}$ q12h x 6-8 times with/without autologous hematopoietic stem cell transplantation (auto-HSCT). Salvage chemotherapy included ICE (idarubicin, cytarabine, etoposide), CAG (aclarubicin, cytarabine, granulocyte-colony stimulating factor), FLAG (fludarabine, cytarabine, granulocyte-colony stimulating factor) and CLARA (cladribine, cytarabine). Allogeneic-HSCT was recommended for all eligible patients with $c$-KIT mutation, continuously positive MRD, and in CR2. Detailed treatment protocol is shown in Fig. S1.

Survival and statistical analyses. Disease-free survival (DFS) was defined as the time between CR1 to the first relapse, censored at the date of the last follow-up or death. Overall survival (OS) was defined as the time between diagnosis and death or the date of the last follow up.

Numerical data are represented in the form of median (range) and were compared using Mann-Whitney nonparametric $U$ test. A nonparametric test was performed using 
Table I. Clinical characteristics of the 64 patients with AML1-ETO-positive AML.

\begin{tabular}{|c|c|c|c|c|}
\hline Characteristics & Total & SDAC-based & IDAC-based & P-value \\
\hline Patients (n) & 64 & 31 & 31 & \\
\hline Median age (years) (range) & $27.5(2-65)$ & $27(5-65)$ & $28(2-60)$ & 0.978 \\
\hline Sex, male/female (ratio) & $39 / 25(1.6)$ & $19 / 12(1.6)$ & $19 / 12(1.6)$ & 1.000 \\
\hline \multicolumn{5}{|l|}{ Blood counts, median values (range) } \\
\hline WBC count $\left(\times 10^{9} / 1\right)$ & $20.3(2.3-72.4)$ & $21.4(3.1-70.3)$ & $19.0(2.3-72.4)$ & 0.163 \\
\hline Hemoglobin level (g/dl) & $75.5(39.0-127.0)$ & $70.0(39.0-123.0)$ & $79.0(41.0-127.0)$ & 0.023 \\
\hline PLT count $\left(\times 10^{9} / 1\right)$ & $23.5(5.0-137.0)$ & $21.0(5.0-93.0)$ & $24.0(9.0-137.0)$ & 0.468 \\
\hline EML (rate, \%) & $20(31.3)$ & $12(38.7)$ & $7(22.6)$ & 0.168 \\
\hline Marrow blasts (range) (\%) & $35.0(3.0-94.0)$ & $35.0(3.0-94.0)$ & $35.0(7.0-93.0)$ & 0.418 \\
\hline CD56-positive $(\mathrm{n}=63)($ rate,$\%)$ & $41(65.1)$ & $20(64.5)$ & $21(70.0)$ & 0.648 \\
\hline \multicolumn{5}{|c|}{ Cytogenetic aberrations in addition to $\mathrm{t}(8 ; 21)(\mathrm{q} 22 ; \mathrm{q} 22)(\mathrm{n}=52)$} \\
\hline Sole $\mathrm{t}(8 ; 21) / \mathrm{ACAs}$ & $28 / 24$ & $13 / 10$ & $15 / 14$ & 0.730 \\
\hline Loss of sex chromosomes (rate, \%) & $19(36.5)$ & $7(30.4)$ & $12(41.8)$ & 0.416 \\
\hline \multicolumn{5}{|c|}{ Molecular mutations in addition to RUNX1-RUNX1T1 (\%) } \\
\hline c-KIT (exon 8; 17) & $20(31.3)$ & $14(45.2)$ & $6(19.4)$ & 0.030 \\
\hline ASXL1 & $10(15.6)$ & $8(25.8)$ & $2(6.5)$ & 0.038 \\
\hline MET & $8(12.5)$ & $5(16.1)$ & $3(9.7)$ & 0.449 \\
\hline MLH1 & $6(9.4)$ & $4(21.9)$ & $2(6.5)$ & 0.390 \\
\hline TET2 & $5(7.8)$ & $3(9.7)$ & $2(6.5)$ & 0.641 \\
\hline FBXW7 & $5(7.8)$ & $2(6.5)$ & $3(9.7)$ & 0.641 \\
\hline TP53 & $5(7.8)$ & $4(21.9)$ & $1(3.2)$ & 0.162 \\
\hline DNMT3A & $5(7.8)$ & $3(9.7)$ & $2(6.5)$ & 0.641 \\
\hline Allo-HSCT (rate, \%) & $13 / 62(21.0)$ & $7(22.6)$ & $6(19.4)$ & 0.755 \\
\hline
\end{tabular}

AML, acute myeloid leukemia; SDAC, standard-dose Ara-C; IDAC, median-dose Ara-C; Ara-C, arabinosylcytosine; WBC, white blood cell; PLT, platelet; EML, extramedullary leukemia; ACA, additional chromosomal abnormality; Allo-HSCT, allogenic hematopoietic stem cell transplantation; c-KIT, KIT proto-oncogene, receptor tyrosine kinase; ASXL1, ASXL transcriptional regulator 1; MET, MET proto-oncogene, receptor tyrosine kinase; MLH1, MutL homolog 1; TET2, Tet methylcytosine dioxygenase 2; FBXW7, F-box and WD repeat domain containing 7; TP53, tumor protein P53; DNMT3A, DNA methyltransferase $3 \alpha$.

the Chi-square test and survival analyses were calculated by Kaplan-Meier survival curves and the log-rank test. Univariate analysis with the log-rank test and multivariate analyses on categorized data were performed using Cox regression. SPSS 17.0 software (SPSS Inc., Chicago, IL, USA) was used for the statistical analysis. A P-value $<0.05$ was considered statistically significant.

\section{Results}

Clinical characteristics of the patients with $A E-A M L$. Of all the 79 newly diagnosed AE-AML patients, only 64 cases were tested for gene mutations with NGS and are involved in this study. The characteristics of the 64 patients are documented in Table I. The median age of onset was 27.5 (range 2-65) years; $20(31.3 \%)$ patients had EML, 25/52 (48.12\%) patients presented with ACAs, and 19/52 (36.5\%) cases with sex chromosomal defects.

The frequency of additional gene mutations at diagnosis. First we verified the sensitivity and specificity of the NGS. The result showed $100 \%$ consistency in the positive and negative detection of FLT3-ITD, c-KIT (exon 8 and 17), NPM1, JAK2 (V617F) and DNMT3A (R882) mutations between the NGS and Sanger sequencing (Fig. S2).

Among the 64 patients being tested for gene sequencing with NGS, a median 2 (1-10) types of additional molecular mutations were detected in $44(68.8 \%)$ patients, including $19(29.7 \%)$ cases with one mutation, $16(25.0 \%)$ with two and $9(14.1 \%)$ with three or more mutations (Fig. 1C). The most common recurrent mutations occurred in $c-K I T(\mathrm{n}=27$, 42.2\%), including 12 (18.8\%) D816, 7 (10.9\%) M541, 5 (7.8\%) N822, 1 (1.5\%) R815_D816insVI, 1 (1.5\%) Y418del and 1 N822_M541 co-mutation; ASXL1 $(\mathrm{n}=10,15.6 \%$, including 1 double mutation), MET ( $\mathrm{n}=8,12.5 \%), \operatorname{MLH1}(\mathrm{n}=6,9.4 \%)$, TET2 (n=5, 7.8\%, including 1 double mutation) and $F B X W 7$, TP53 and DNMT3A (n=5,7.8\%). This was followed by $4(6.3 \%)$ $P A X 5$ and CEBPA, 3 (4.7\%) KMT2A, ATM, FLT3 and NRAS, 2 (3.1\%) DNMT3L, PDGFRA, APC, HRAS and RUNX1, 1 (3.1\%) SH2B3, SMAD4, KRAS and NPM1 (Fig. 1A and D). The nature of these mutations is shown in Table SIII. When genes were categorized into functional groups, the most common mutations were those involved in the tyrosine kinase pathway $(n=34,53.1 \%)$, chromatin modification $(n=16$, 


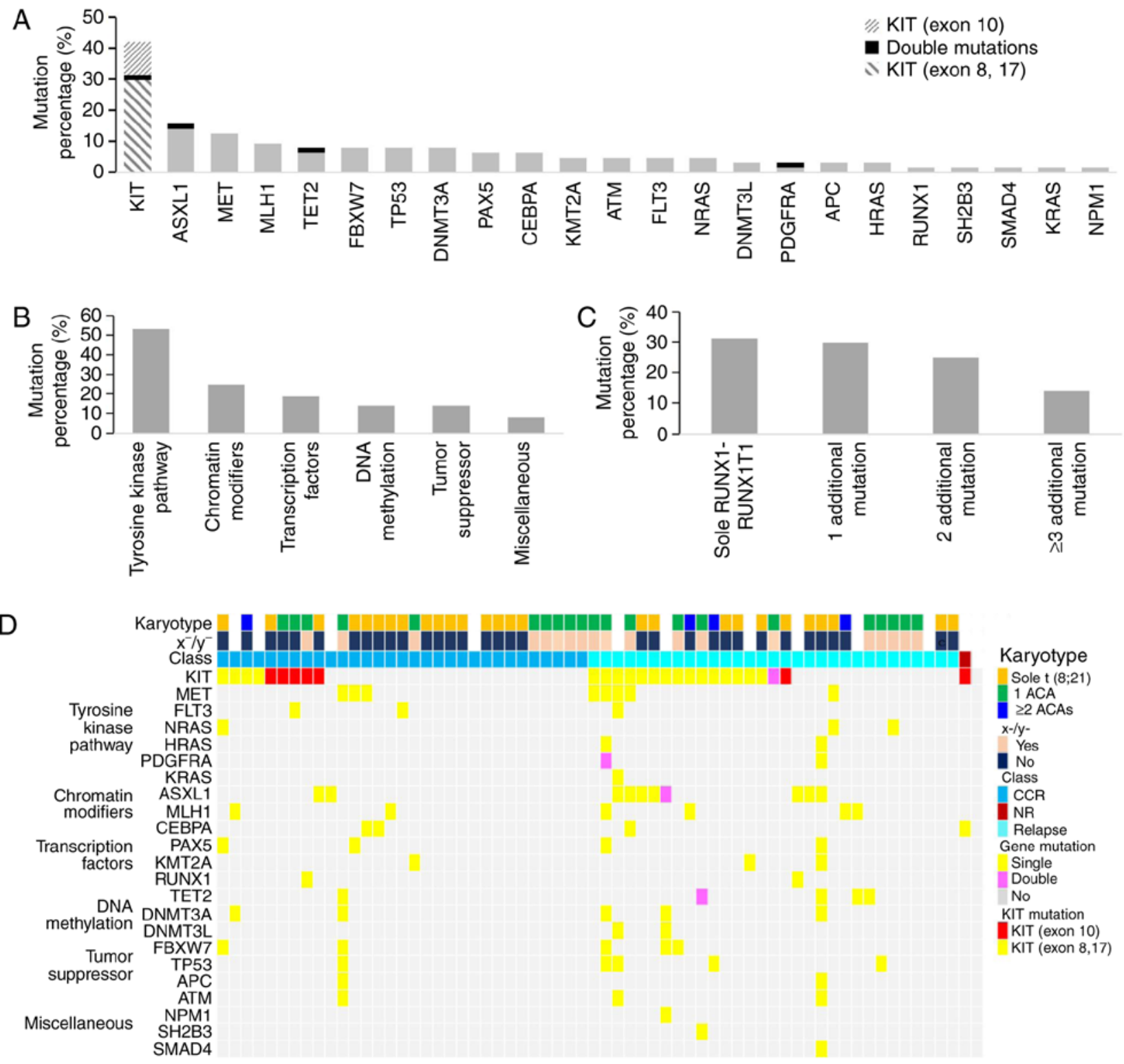

Figure 1. Gene mutation profile in newly diagnosed AML1-ETO-positive AML patients. Gene mutation sequencing was performed in 64 patients with NGS (A) A total of 27 (42.2\%) patients presented with $c$-KIT mutation, including $19(29.7 \%)$ mutated at exon 8 or $17,7(10.9 \%)$ at exon 10 and one (1.6\%) with double mutations. Ten (15.6\%) cases presented with an ASXL1 mutation, including $9(14.1 \%)$ with a single mutation and one (1.6\%) with double mutations. Eight (12.5\%) patients presented with the MET mutation. Six (9.4\%) cases harbored an MLH1 mutation. TET2, FBXW7, TP53 and DNMT3A genes were respectively mutated in $5(7.8 \%)$ patients, including one patient with a double mutation in the TET2 gene. Four (6.3\%) patients presented with $P A X 5$ and CEBPA mutations, respectively. Three (4.7\%) harbored KMT2A, ATM, FLT3 and NRAS mutations, respectively. Two (3.1\%) had a DNMT3L, PDGFRA, APC and HRAS mutation, respectively, including one with double mutations in the gene. One (1.6\%) case harbored the RUNXI, SH3B3, SMAD4, KRAS and NPMI mutations, respectively. (B and D) All the mutant genes were classified into different groups according to their function. A total of 34 (53.1\%) patients presented with a tyrosine kinase pathway gene mutation, 16 (25.0\%) showed a chromatin modification gene mutation, 12 (18.8\%) harbored a transcription gene mutation, 9 (14.1\%) presented with DNA methylation and tumor-suppression gene mutations, respectively, and $5(7.8 \%)$ showed miscellaneous function gene mutation (C) Among those patients with gene mutations, there were 19 (29.7\%) harboring one mutation, $16(25.0 \%)$ with 2 mutations and $9(14.1 \%)$ with $\geq 3$ mutations (D) Mutation profile according to clinical features included karyotype, loss of sex chromosome and treatment response. All mutant genes detected are shown. Some mutations co-occurred or were exclusive and some were associated with higher relapse. AML, acute myeloid leukemia; NGS, next-generation sequencing. AML1, acute myeloid leukemia 1 protein [also known as RUNX family transcription factor 1 (RUNX1)]; ETO, eight twenty one protein [also known as RUNX1 partner transcriptional co-repressor 1 (RUNX1T1)]; c-KIT, KIT proto-oncogene, receptor tyrosine kinase; ASXL1, ASXL transcriptional regulator 1; MET, MET proto-oncogene, receptor tyrosine kinase; MLH1, MutL homolog 1; TET2, Tet methylcytosine dioxygenase 2; FBXW7, F-box and WD repeat domain containing 7; TP53, tumor protein P53; DNMT3A, DNA methyltransferase 3 $\alpha$; PAX5, paired box 5; CEBPA, CCAAT enhancer binding protein $\alpha$; KMT2A, lysine methyltransferase 2A; ATM, ATM serine/threonine kinase; FLT3, Fms related tyrosine kinase 3; NRAS, NRAS proto-oncogene, GTPase; DNMT3L, DNA methyltransferase 3 like; PDGFRA, platelet derived growth factor receptor $\alpha$; APC, APC regulator of WNT signaling pathway; HRAS, HRas proto-oncogene, GTPase; PDGFA, platelet derived growth factor subunit A; SH2B3, SH2B adaptor protein 3; SMAD4, SMAD family member 4; KRAS, KRAS proto-oncogene, GTPase; NPM1, nucleophosmin 1.

$25.0 \%)$, transcription $(\mathrm{n}=12,18.8 \%)$, DNA methylation $(\mathrm{n}=9$, $14.1 \%)$, tumor suppression $(\mathrm{n}=9,14.1 \%)$ and miscellaneous function $(\mathrm{n}=5,7.8 \%)$ (Fig. 1B and D).
Clinical implications of gene mutations and gene co-mutation. We analyzed the clinical influence of the most common recurrent mutations including $c-K I T, A S X L 1, M E T$, 
Table II. Influence of the gene mutations on RFS and OS.

\begin{tabular}{|c|c|c|c|c|c|c|}
\hline & \multicolumn{3}{|c|}{ RFS } & \multicolumn{3}{|c|}{ OS } \\
\hline & HR & $95 \% \mathrm{CI}$ & P-value & HR & $95 \% \mathrm{CI}$ & P-value \\
\hline \multicolumn{7}{|l|}{ Univariate $^{\mathrm{a}, \mathrm{b}}$} \\
\hline c-KIT (exon 8,17 vs. exon $10, \mathrm{WT}$ ) & 3.31 & $1.60-6.81$ & 0.001 & 3.25 & $1.48-7.18$ & 0.003 \\
\hline ASXL1 (mutated vs. WT) & 2.94 & $1.30-6.66$ & 0.010 & 3.65 & $1.57-8.49$ & 0.003 \\
\hline MET (mutated vs. WT) & 2.36 & $0.89-6.28$ & 0.085 & 3.44 & $1.36-8.71$ & 0.009 \\
\hline TET2 (mutated vs. WT) & 2.00 & $0.69-5.79$ & 0.202 & 2.29 & $0.78-6.71$ & 0.130 \\
\hline MLH1 (mutated vs. WT) & 1.61 & $0.56-4.65$ & 0.380 & 2.25 & $0.77-6.58$ & 0.141 \\
\hline FBXW7 (mutated vs. WT) & 2.66 & $0.77-9.19$ & 0.122 & 4.13 & $1.35-12.62$ & 0.013 \\
\hline TP53 (mutated vs. WT) & 3.05 & $1.04-8.91$ & 0.042 & 4.20 & $1.56-11.28$ & 0.004 \\
\hline DNMT3A (mutated vs. WT) & 1.34 & $0.40-4.45$ & 0.636 & 2.58 & $0.88-7.54$ & 0.083 \\
\hline KMT2A (mutated vs. WT) & 1.06 & $0.25-4.50$ & 0.940 & 1.56 & $0.37-6.63$ & 0.549 \\
\hline CEBPA (mutated vs. WT) & 1.06 & $0.14-7.85$ & 0.955 & 1.11 & $0.15-8.25$ & 0.918 \\
\hline PAX5 (mutated vs. WT) & 1.15 & $0.27-4.86$ & 0.852 & 1.40 & $0.33-5.97$ & 0.650 \\
\hline \multicolumn{7}{|l|}{ Multivariate $^{c}$} \\
\hline c-KIT (exon 8,17 vs. exon 10, WT) & 3.36 & $1.54-7.34$ & 0.002 & 2.84 & $1.20-6.71$ & 0.018 \\
\hline ASXL1 (mutated vs. WT) & 3.13 & $1.34-7.32$ & 0.009 & 3.94 & $1.62-9.61$ & 0.003 \\
\hline
\end{tabular}

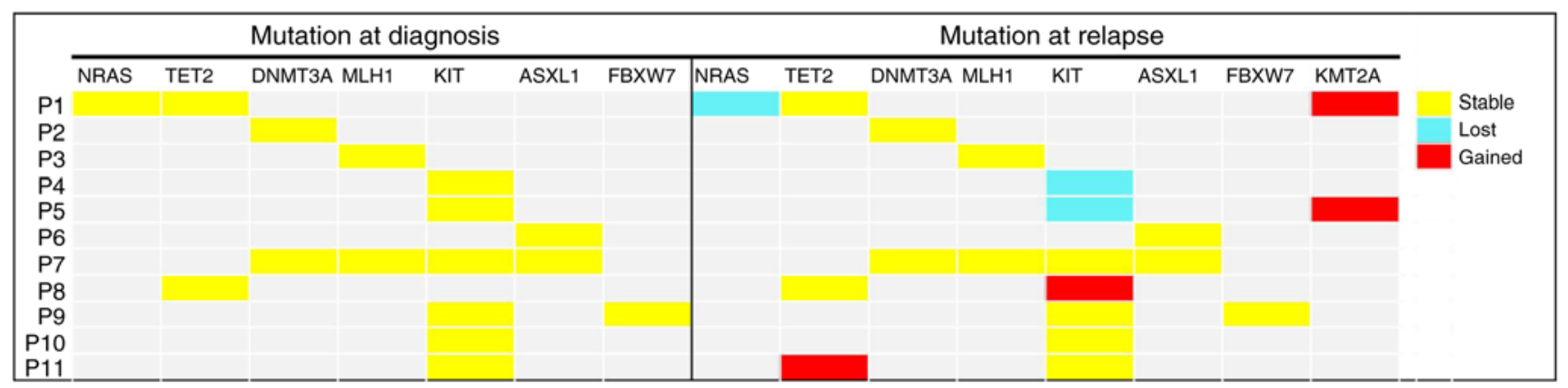

Figure 2. Pattern of gained and/or lost molecular mutations in AML1-ETO-positive AML at diagnosis and in the case of relapse. AML, acute myeloid leukemia.

MLH1, TET2, FBXW7, TP53 and DNMT3A, and found no significant difference in the clinical characteristics between the gene mutation and wild-type (WT) groups, except for a higher incidence of ACAs $(\mathrm{P}=0.025)$ in the TP53 mutation group as compared with the TP53 WT (Table SIV). According to gene function, we found significantly higher bone marrow blast in the transcription and miscellaneous mutation group, as well as higher bone marrow blast and loss of sex chromosome in DNA methylation mutation group as compared with the WT group, respectively (Table SV).

Associations between molecular mutations were also assayed among those eight recurrent mutations. The DNMT3A mutation was found to be mutually exclusive of $M L H 1$ $(\mathrm{P}=0.014)$, TET2 $(\mathrm{P}=0.005), F B X W 7(\mathrm{P}<0.001)$ and TP53
$(\mathrm{P}=0.005)$, and also a trend of association with MET mutations $(\mathrm{P}=0.053)$ was noted. Apart from the DNMT3A mutation, the $F B X W 7$ mutation was mutually exclusive of $c-K I T$ (exon 8 and 17) $(\mathrm{P}=0.014)$ and TP53 $(\mathrm{P}=0.005)$, and a trend of association with the MET mutation $(\mathrm{P}=0.053)$ was noted. In addition to the DNMT3A and FBXW7 mutations, TP53 was also mutually exclusive of $M E T(\mathrm{P}=0.001)$ (Fig. 1D and Table SIV).

Genetic alterations at relapse. Among the 31 relapsed patients, 11 had a mutation detection with NGS at relapse. In $6 / 11(54.5 \%)$ patients, the initial molecular mutation pattern was altered at relapse; $4(36.3 \%)$ patients gained new mutations and $3(27.3 \%)$ experienced loss of one initial mutation. 

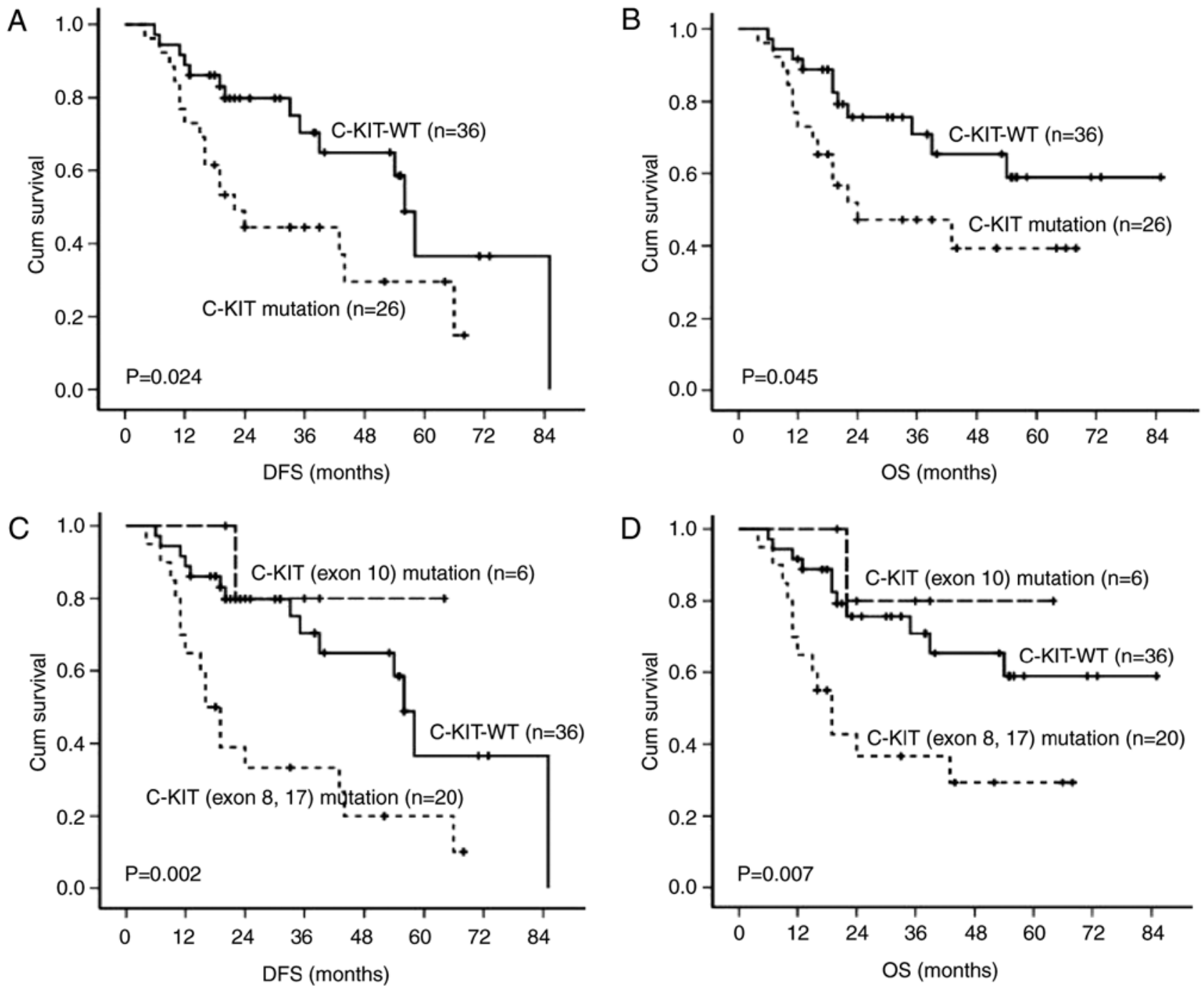

Figure 3. $c$-KIT (exon 8, 17) mutation confers an adverse effect on DFS and OS. $c$-KIT-WT vs. $c$-KIT mutation: (A) DFS: $55.0 \pm 6.1$ vs. $34.2 \pm 5.0 \%, \mathrm{P}=0.024$; (B) OS: $61.1 \pm 5.8$ vs. $37.6 \pm 5.4 \%, \mathrm{P}=0.045$. $c$-KIT-WT vs. $c$-KIT (exon 8,17 ) mutation vs. $c-$ KIT (exon 10) mutation: (C) DFS: $55.0 \pm 6.1$ vs. $28.2 \pm 5.1$ vs $55.6 \pm 7.5 \%, \mathrm{P}=0.002$; (D) OS: $61.1 \pm 5.8$ vs. $31.6 \pm 5.9$ vs. $55.6 \pm 7.5 \%, \mathrm{P}=0.007$. $c-K I T$, KIT proto-oncogene, receptor tyrosine kinase; DFS, disease-free survival; OS, overall survival; WT, wild-type.

Mutations commonly gained at relapse were $K M T 2 A(2 / 11$, $18.2 \%$ ), followed by $c$-KIT and TET2 (each $\mathrm{n}=1,9.1 \%$ ). Loss of initial mutation at relapse was observed in $c$-KIT $(2 / 11$, $18.2 \%)$, as well as $N R A S(1 / 11,9.11 \%)$. The $c-K I T$ mutation was the most common molecular event in the relapsed patients; $7 / 11(63.6 \%)$ were associated with $c$-KIT mutation at relapse (1 gained, 2 lost and 4 stable) (Fig. 2).

Patient survival and the influence of gene mutations on survival. Among the 64 patients, 1 patient declined further chemotherapy and was excluded from the outcome analysis; 63 patients completed one to two courses of induction chemotherapy, and 59 (93.7\%) gained CR. Among the 4 patients with no remission, 1 patient declined further treatment and was excluded from the survival analysis, and the other 3 patients received salvage therapy (two with CAG regimen and one with FLAG) and all obtained CR. After acquiring CR, 31 patients received SDAC-based consolidation; the other 31 received IDAC-based regimens; 13 cases underwent allo-HSCT, of which 7 were in the SDAC-based group and 6 were in the
IDAC-based group. Between the two groups, except for a lower hemoglobin level, and a higher incidence of $c$-KIT (exon 8, 17) and ASXL1 mutation in the SDAC-based group, there was no significant difference in the clinical characteristics (Table I). With a median follow-up of 23.5 (4-85) months, cumulative 18/55 (32.7\%) patients obtained MMR after two courses of consideration, $31(50.0 \%)$ patients relapsed, and 25 (40.3\%) cases succumbed to the disease. The 3-year DFS and OS percentages were $50.0 \pm 7.0$ and $55.0 \pm 7.0 \%$, respectively. Two patients died of treatment-related diseases, the 23 died of leukemia progression. Survival analysis showed that the patients with $c$-KIT mutation had a lower rate of DFS $(\mathrm{P}=0.024)$ and $\mathrm{OS}(\mathrm{P}=0.045)$ when compared with the DFS and OR of those with $c$-KIT-WT (Fig. 3A and B). When $c$-KIT mutations were sub-grouped into exon 8, 17 and exon 10, DFS and OS analysis showed no obvious difference in the patients with $c$-KIT (exon 10) mutation and WT $(\mathrm{P}>0.05)$, yet DFS and OS were prolonged in both these groups when compared with the DFS and OS in the $c$-KIT (exon 8, 17) mutation group $(\mathrm{P}<0.05)$ (Fig. 3C and D), suggesting that $c-K I T$ (exon 8, 17) 

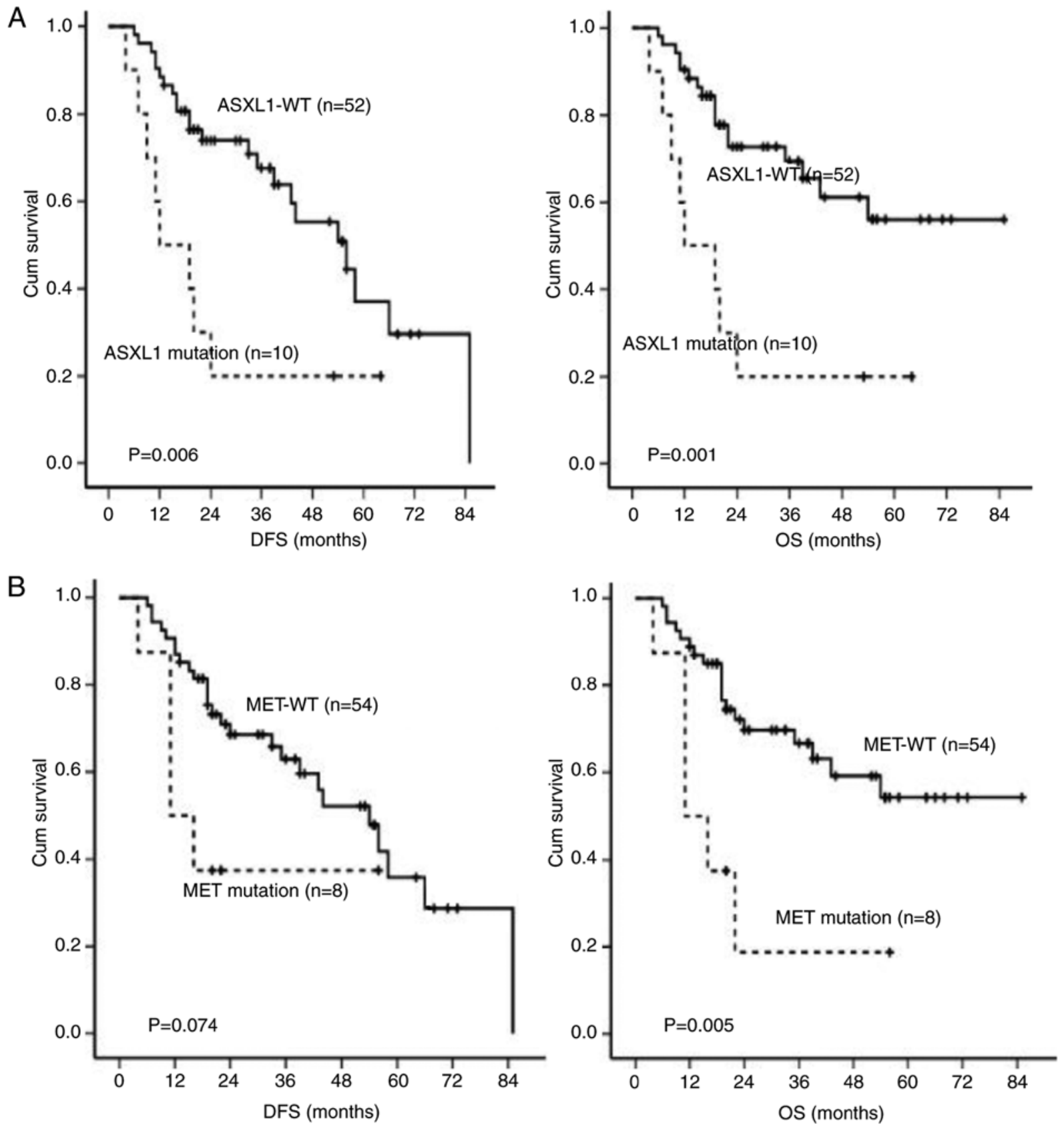

Figure 4. ASXL1, MET, TP53 and FBXW7 mutations displayed a poor prognostic effect. (A) ASXL1-WT vs. ASXL1 mutation: DFS: $51.3 \pm 4.8$ vs. $23.4 \pm 6.7 \%$, $\mathrm{P}=0.006$; OS: $59.1 \pm 5.0$ vs. $23.4 \pm 6.7 \%, \mathrm{P}=0.001$. (B) $M E T$-WT vs. $M E T$ mutation: $\mathrm{DFS}: 49.4 \pm 4.7$ vs. $27.6 \pm 7.8 \%, \mathrm{P}=0.074 ;$ OS: $57.5 \pm 4.9$ vs. $21.3 \pm 6.7 \%, \mathrm{P}=0.005$. ASXL1, ASXL transcriptional regulator 1; MET, MET proto-oncogene, receptor tyrosine kinase; TP53, tumor protein P53; FBXW7, F-box and WD repeat domain containing 7; DFS, disease-free survival; OS, overall survival; WT, wild-type.

but not exon 10 mutation adversely affects patient survival. Univariate analysis showed that $A S X L 1$ and TP53 mutations were adverse factors for DFS $(\mathrm{P}<0.05)$, and $A S X L 1, M E T$, FBXW7 and TP53 mutations had a poor effect on OS $(\mathrm{P}<0.05)$ (Fig. 4 and Table II). When the number of gene mutation was taken into account, increasingly adverse RFS and OS were observed with increasing number (Fig. 5).

Multivariate analysis data revealed that $c$-KIT (exon 8, 17) (RFS: HR 3.36, 95\% CI 1.54-7.34, P=0.002; OS: HR 2.84, 95\% CI 1.20-6.71, $\mathrm{P}=0.018$ ) and $A S X L 1$ mutations (RFS: HR 3.13, 95\% CI 1.34-7.32, $\mathrm{P}=0.009$; OS: HR 3.94, 95\% CI 1.62-9.61, $\mathrm{P}=0.003)$ were independent adverse factors for both RFS and OS (Table II). When consolidation regimens were taken into consideration, the same result was shown. Among the patients with IDAC-based regimens, the cohort with $c-K I T$ (exon 8,17 ) mutation had significantly poorer DFS and OS; also among those with SDAC-based regimens, patients with the mutation had apparently, although not significantly, worse DFS and OS. Meanwhile, significantly poorer DFS and OS were observed in the ASXL1-mutant patients with SDAC-based regimens (Fig. S3). Furthermore, according to $c$-KIT (exon 8, 17) and ASXL1 mutation or not, we divided all the 62 patients into three groups, as no mutation $(n=37)$, one mutation $(n=20)$ and two mutation groups $(n=5)$, and found that the patients with two mutations had the worst DFS and OS, followed by those with one mutation; no mutation patients had the best DFS 

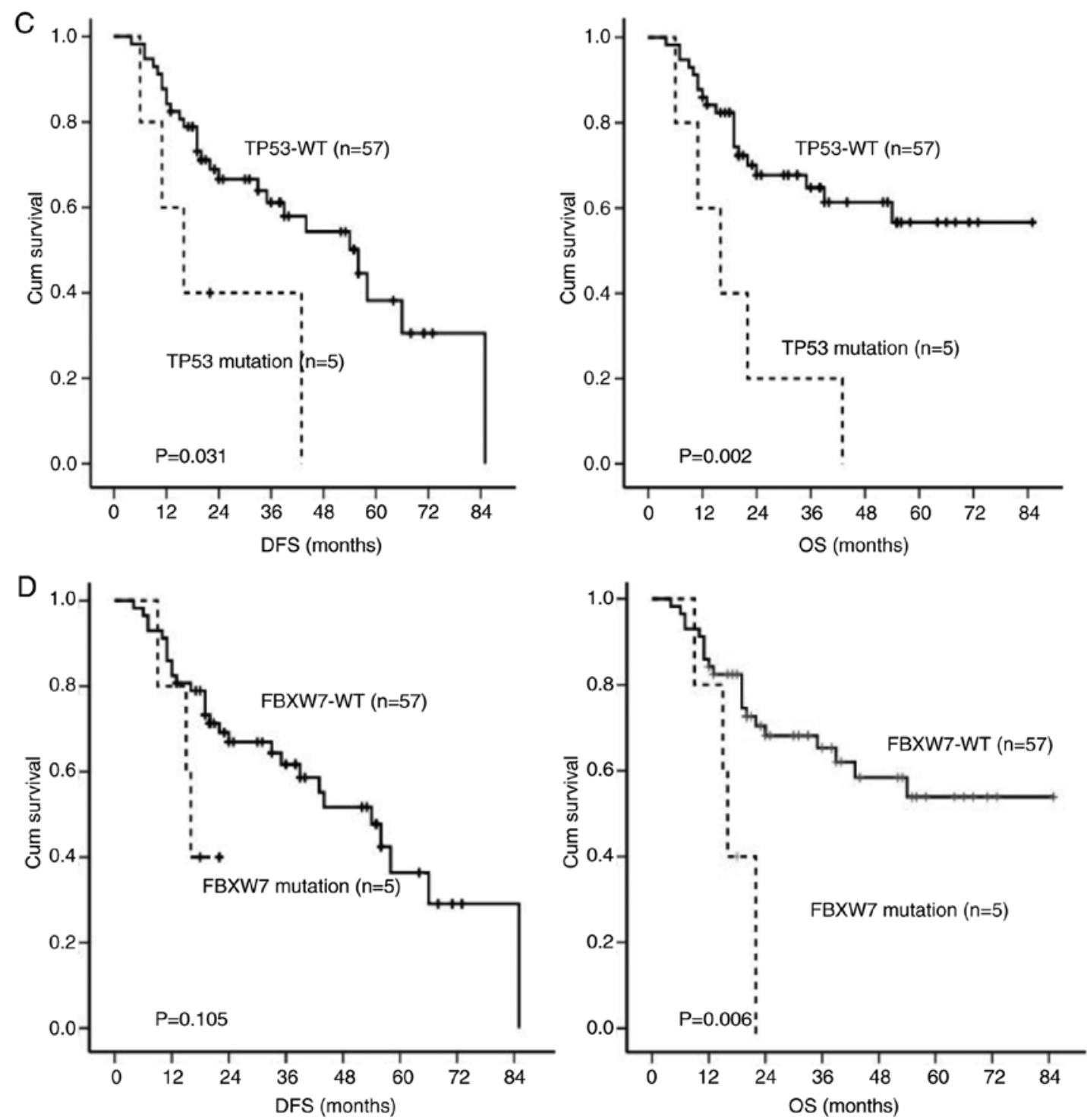

Figure 4. Continued. ASXL1, MET, TP53 and FBXW7 mutations displayed a poor prognostic effect. (C) TP53-WT vs. TP53 mutation: DFS: $49.6 \pm 4.7$ vs. $23.8 \pm 8.3 \%, \mathrm{P}=0.031$; OS: $57.8 \pm 4.8$ vs. $19.6 \pm 6.4 \%, \mathrm{P}=0.002$. (D) $F B X W 7$-WT vs. $F B X W 7$ mutation: DFS: $48.7 \pm 4.6$ vs. $16.8 \pm 2.2 \%, \mathrm{P}=0.105 ; \mathrm{OS}: 56.6 \pm 4.8$ vs. $16.8 \pm 2.5 \%, \mathrm{P}=0.006$. ASXL1, ASXL transcriptional regulator 1; MET, MET proto-oncogene, receptor tyrosine kinase; TP53, tumor protein P53; FBXW7, F-box and WD repeat domain containing 7; DFS, disease-free survival; OS, overall survival; WT, wild-type.

and OS (Fig. 6A and B), indicating that co-mutation of $c$-KIT (exon 8,17 ) and $A S X L 1$ had a worse effect on DFS and OS than a single mutation. When the therapeutic regimens were taken into account, the same result was observed in either SDAC-based or IDAC-based group, although the difference was not significant in the IDAC-based group (Fig. 6C-F).

\section{Discussion}

The AML1-ETO fusion gene cannot singly induce leukemia but instead cooperates with secondary mutations to induce leukemia, presenting a '2-hit model' in leukemia development $(3,16,17)$. Moreover, data have revealed a multitude of genetic and epigenetic aberrations in leukemogenesis $(18,19)$. In accordance with these, the present study showed that up to $44 / 64(68.8 \%)$ patients presented a median of 2 (1-10) recurrent mutations at diagnosis and 6/11 $(54.5 \%)$ cases underwent genetic alterations at relapse. The most common mutations at diagnosis occurred in tyrosine kinase, followed by chromatin modification, transcription, DNA methylation, tumor suppression and miscellaneous function. Among those mutations, tyrosine kinase, DNA methylation and tumor suppression were found to be commonly co-mutated, shown as mutual exclusion of $c$-KIT (exon 8,17 ) or MET with DNMT3A or FBXW7 or TP53, and DNMT3A with $F B X W 7$ or TP53, supporting multi-oncogenic cooperation in leukemogenesis.

In line with previous studies $(4,19)$, the $c$-KIT mutation was the most common molecular event in this study, with an incidence of $27 / 64(42.2 \%)$ at diagnosis, and $7 / 11$ being associated with molecular alteration at relapse, further supporting, from the clinical point of view, that $c$-KIT mutation plays a critical role in the development and progression of AML1-ETO-positive acute myeloid leukemia (AE-AML). As the $c-K I T$ mutation is well accepted as a poor factor in this subtype of leukemia $(1,11,20)$, to further clarify which exon mutation performs the key role, according to the mutant 

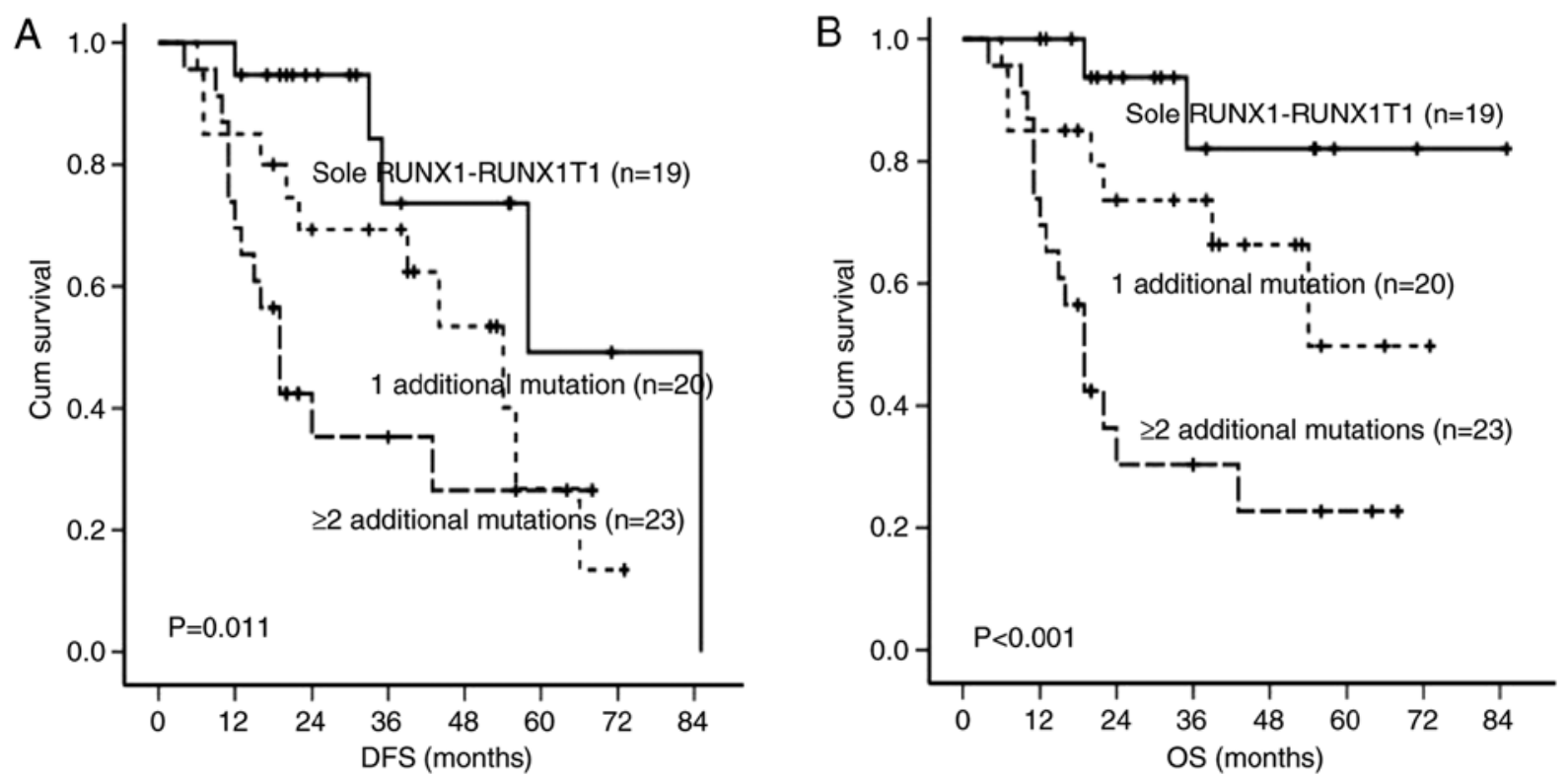

Figure 5. Increasing mutation number confers an increasingly adverse effect on patient prognosis. Sole RUNX1-RUNX1T1 vs. 1 additional mutation vs. $\geq 2$ additional mutations: (A) DFS: $63.8 \pm 9.2$ vs. $44.0 \pm 5.5$ vs. $31.1 \pm 5.4 \%$, $\mathrm{P}=0.011$; (B) OS: $75.0 \pm 6.6$ vs. $51.5 \pm 6.3$ vs. $29.0 \pm 5.1 \%$, $\mathrm{P}<0.001$. RUNX1, RUNX family transcription factor 1 [also known as acute myeloid leukemia 1 protein (AML1)]; RUNX1T1, RUNX1 partner transcriptional co-repressor 1 [also known as eight twenty one protein (ETO)]; DFS, disease-free survival; OS, overall survival.

exon, we divided the patients with $c$-KIT mutation into exon 8,17 and exon 10 groups, and found that, agreeing with previous studies $(4,21), c$-KIT (exon 8,17 ) but not exon 10 had an adverse effect on disease-free survival (DFS) (exon 8,17 vs. exon 10 vs. WT: $28.2 \pm 5.1 \%$ vs. $55.6 \pm 7.5 \%$ vs. $55.0 \pm 6.1 \%$, $\mathrm{P}=0.002)$ and overall survival (OS) $(31.6 \pm 5.9 \%$ vs. $55.6 \pm 7.5 \%$ vs. $61.1 \pm 5.8 \%, \mathrm{P}=0.007)$. Furthermore, univariate analysis supported the independent adverse effect of $c$-KIT (exon 8 , 17) mutation on survival [DFS: HR 3.36 (1.54-7.34), $\mathrm{P}=0.002$; OS: HR 2.84 (1.20-6.71), $\mathrm{P}=0.018]$. Also the same result was observed when treatment regimens were taken into consideration.

The ASXL1 mutation has also been reported to occur frequently in AE-AML and is associated with a poor disease outcome. Krauth et al (4) reported that $11.5 \%$ patients with AE-AML presented with the ASXL1 mutation, and compared with WT, ASXL1-mutated patients had poorer RFS (de novo AML: 20 vs. $59.1 \%, \mathrm{P}=0.011$; total cohort: 28.6 vs. $56.7 \%$, $\mathrm{P}=0.021)$. Micol et al (22) found that $11 / 110(10.0 \%)$ patients with AE-AML presented with an ASXL1 mutation, and those with this mutation had a trend for increasing risk for relapse (54.6 vs. $25 \%, \mathrm{P}=0.226$ ). In the present study, $A S X L 1$ mutation was the second most common mutation with an incidence of $15.6 \%$, and was found to adversely impact RFS $(51.3 \pm 4.8 \%$ vs. $23.4 \pm 6.7 \%, \mathrm{P}=0.006)$ and $\mathrm{OS}(59.1 \pm 5.0 \%$ vs. $23.4 \pm 6.7 \%$, $\mathrm{P}=0.001)$. In addition, univariate analysis data showed that the ASXL1 mutation was an independent adverse factor for survival [DFS: HR 3.13 (1.34-7.32), $\mathrm{P}=0.009$; OS: HR 3.94 (1.62-9.61), $\mathrm{P}=0.003$ ]. Also the same result was observed when the treatment regimens were taken into account, suggesting that the role of the ASXL1 mutation in AE-AML warrants further attention.

The MET (c-MET) and TP53 mutations were found to be two more important adverse factor for DFS and OS in the present study. It is known that $M E T$ plays an important role in cell proliferation and differentiation, and its aberrant expression, which could be activated by gene mutation, is found to be associated with promotion of tumorigenesis (23). The MET mutation has been reported to be involved in the development and metastasis of various solid cancers, and adversely affects the disease outcome $(24,25)$. Autocrine activation of the MET signaling pathway was found in almost $40 \%$ of patients with AML $(26,27)$, and increased MET activation was associated with leukemia relapse, especially in the $\mathrm{t}(15 ; 17)$ and $\mathrm{t}(8 ; 21)$ cytogenetic subtypes (28). However, the MET mutation in AML is rarely reported. To our interest, in this series, 8 out of $64(12.5 \%)$ patients harbored $M E T$ mutation and presented a poor outcome, suggesting that MET aberrant activation in AE-AML may be associated with MET mutation; furthermore, MET mutation may act as a poor prognostic factor in AE-AML. TP53 is a central tumor-suppressor gene, which is involved in cell cycle regulation and apoptosis induction (29). The tumor-suppressor activity of the protein is typically abolished and reverts to having a negative impact on survival when TP53 mutates (30-32), of which the most frequent type in tumors is missense and deletion mutations, although gain-of-function mutations have also been described (33). It has been reported that AML1-ETO activates the p53 pathway and then sensitizes leukemia cells to DNA damage (34), while loss of the p53 response pathway is associated with disease progression. However, the incidence and biological effect of the TP53 mutation in AE-AML remains unclear. In this series, 5 (7.8\%) patients were detected to harbor TP53 mutations; 2 presented with missense mutations and 3 with deletions, and these patients presented with poor DFS and OS.

In addition, in agreement with previous research (4), the number of gene mutations was important in regards to the prognostic effect in our study; an increasingly poor RFS and OS with an increase in the mutation number was observed in the whole cohort. Also, co-mutation of $c$-KIT (exon 8, 17) and 

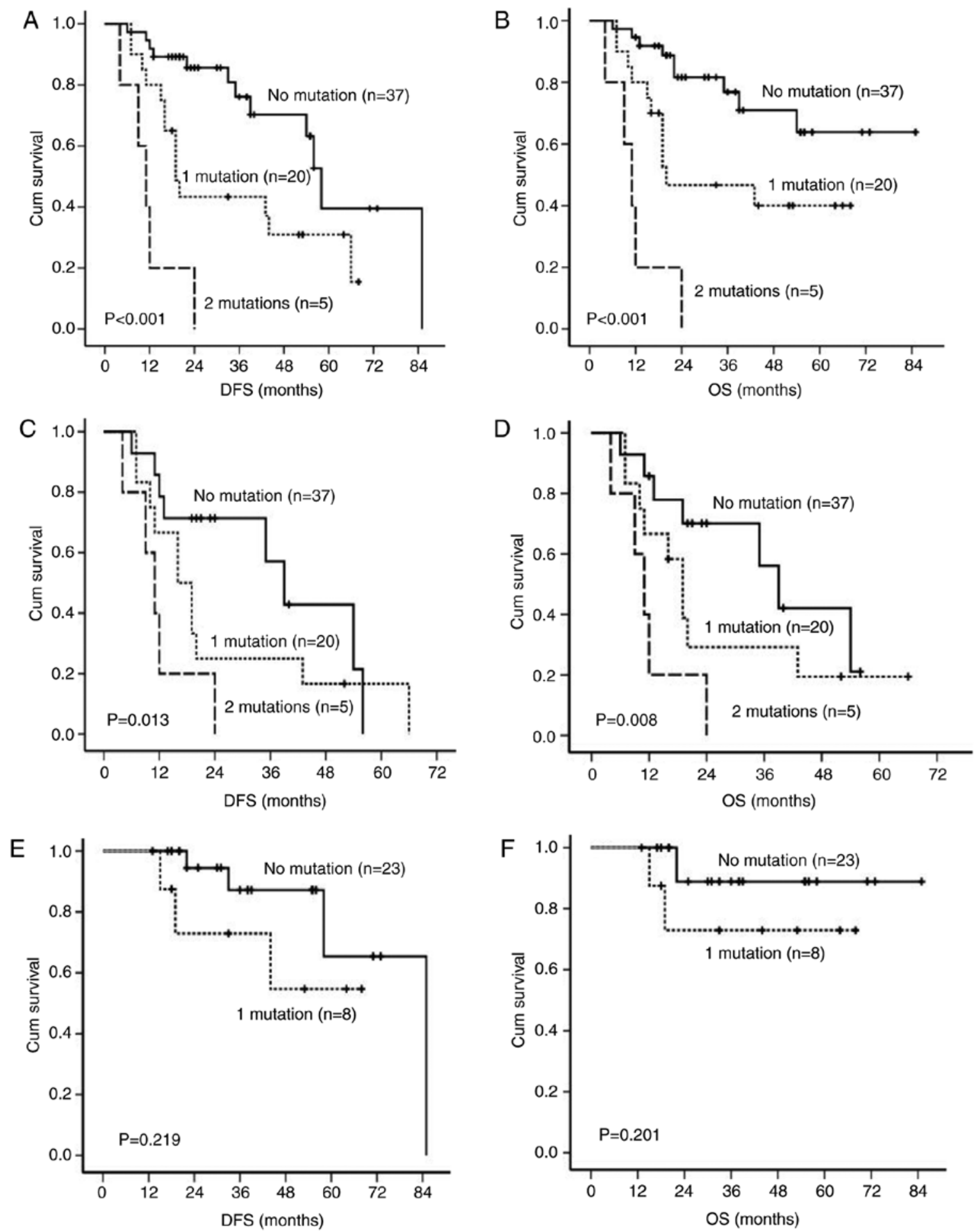

Figure 6. Co-mutation of $c$-KIT (exon 8, 17) and ASXL1 mutation exhibited a worse effect on survival than the single mutation. $c$-KIT (exon 8, 17) and ASXL1 mutations were multi-variately analyzed to be independent adverse factors for both DFS and OS. According to the absence or presence of the mutants of these two genes, all patients were divided into three groups: no mutation vs. 1 mutation vs. 2 mutations: (A) DFS: $58.4 \pm 6.1$ vs. $34.4 \pm 5.5$ vs. $12.0 \pm 3.3 \%$, P $<0.001$; (B) OS: $65.0 \pm 5.6$ vs. $37.9 \pm 6.0$ vs. $12.0 \pm 3.3 \%, \mathrm{P}<0.001$. Among the patients receiving SDAC-based regimens for consolidation therapy, there was a significant difference in the DFS and OS among these groups. No mutation vs. 1 mutation vs. 2 mutations: (C) DFS: $37.1 \pm 5.7$ vs. $25.0 \pm 6.2$ vs. $12.0 \pm 3.3 \%, P=0.013$; (D) OS: $37.2 \pm 5.7$ vs. $26.9 \pm 6.5$ vs. $12.0 \pm 3.3 \%, \mathrm{P}=0.008$. Among those receiving IDAC-based regimens, an apparent, though not significant, difference in the DFS and OS was observed between the patients with no mutation and 1 mutation. No mutation vs. 1 mutation: (E) DFS:71.8 \pm 7.7 vs. $49.9 \pm 8.3 \%$, P=0.219; (F) OS: $78.0 \pm 4.7$ vs. $54.2 \pm 84 \%, \mathrm{P}=0.201$. c-KIT, KIT proto-oncogene, receptor tyrosine kinase; ASXL1, ASXL transcriptional regulator 1; DFS, disease-free survival; OS, overall survival; SDAC-based, standard-dose Ara-C-based regimen; IDAC-based, intermedium-dose Ara-C-based regimen.

ASXL1 mutations conferred a worse effect on RFS and OS, as compared with a single mutation, further supporting the multi-oncogenic cooperation in cancer progression.
In summary, additional gene mutations play a critical role in AE-AML. This was demonstrated by the fact that $44 / 64(68.8 \%)$ patients presented with recurrent mutations at 
diagnosis and 6/11 (54.5\%) cases underwent genetic alterations at relapse. The $c$-KIT mutation appears to be the most common molecular event in this subtype of leukemia, followed by ASXL1. c-KIT (exon 8, 17) but not exon 10, and also the ASXL1 mutation have a negative impact on survival; co-mutation of these two gene shows an even worse effect. The prognostic effect of $M E T$ and TP53 mutations in AE-AML warrants further study.

\section{Acknowledgements}

Trial registration website: chictr.org.cn: Registration number: ChiCTR1900024337. Registered date: August 21, 2019. This clinical trial was retrospectively registered.

\section{Funding}

This study was funded by the National Natural Science Foundation of China (no. 81500138), the Natural Science Foundation of Guangdong Province, China (no. 2014A030313270), the Science and Technology Program of Guangzhou, China (no. 2013J4100109), the National High-Tech R\&D Program (863 Program) China (no. 2012AA02A505), the President Funding of Nanfang Hospital (no. 2015C025) and the Clinical Research Initiative of Southern Medical University (no. LC2016YM006).

\section{Availability of data and materials}

The corresponding author can be contacted for all requests for data.

\section{Authors' contributions}

GY and CY performed investigations, gene mutation and expression detection, analyzed data and wrote the paper. FW performed the gene mutation analysis and analyzed the data. LJ and ZZ analyzed the data. DX, XJ, JZ and QL performed the investigations. FM designed the study and wrote the paper. All authors read and approved the final manuscript and agree to be accountable for all aspects of the research in ensuring that the accuracy or integrity of any part of the work are appropriately investigated and resolved.

\section{Ethics approval and consent to participate}

All samples and clinical data were obtained upon approval of the Nanfang Hospital, Southern Medical College of Medicine Institutional Review Boards. The reference number is [2012] ethical review (115). All patients and/or guardians provided written informed consent. The content of the informed consent included the agreement of patient clinical data being published in any form.

\section{Patient consent for publication}

Not applicable.

\section{Competing interests}

The authors declare that they have no competing interests.

\section{References}

1. Park SH, Chi HS, Cho YU, Jang S and Park CJ: Effects of c-KIT mutations on expression of the RUNX1/RUNX1T1 fusion transcript in $\mathrm{t}(8 ; 21)$-positive acute myeloid leukemia patients. Leuk Res 37: 784-789, 2013.

2. Arber DA, Orazi A, Hasserjian R, Thiele J, Borowitz MJ, Le Beau MM, Bloomfield CD, Cazzola M and Vardiman JW: The 2016 revision to the world health organization classification of myeloid neoplasms and acute leukemia. Blood 127: 2391-2405, 2016.

3. Wang YY, Zhou GB, Yin T, Chen B, Shi JY, Liang WX, Jin XL, You JH, Yang G, Shen ZX, et al: AML1-ETO and C-KIT mutation/overexpression in $\mathrm{t}(8 ; 21)$ leukemia: Implication in stepwise leukemogenesis and response to Gleevec. Proc Natl Acad Sci USA 102: 1104-1109, 2005.

4. Krauth MT, Eder C, Alpermann T, Bacher U, Nadarajah N, Kern W, Haferlach C, Haferlach T and Schnittger S: High number of additional genetic lesions in acute myeloid leukemia with $\mathrm{t}(8 ; 21) /$ RUNX1-RUNX1T1: Frequency and impact on clinical outcome. Leukemia 28: 1449-1458, 2014.

5. Wang YY, Zhao LJ, Wu CF, Liu P, Shi L, Liang Y, Xiong SM, Mi JQ, Chen Z, Ren R and Chen SJ: C-KIT mutation cooperates with full-length AML1-ETO to induce acute myeloid leukemia in mice. Proc Natl Acad Sci USA 108: 2450-2455, 2011.

6. Kim M, Kim J, Kim JR, Han E, Park J, Lim J, Kim Y, Han K, Kim HJ, Min WS and Cho B: FLT3 expression and IL10 promoter polymorphism in acute myeloid leukemia with RUNX1-RUNX1T1. Mol Biol Rep 42: 451-456, 2015.

7. Grisolano JL, O'Neal J, Cain J and Tomasson MH: An activated receptor tyrosine kinase, TEL/PDGFbetaR, cooperates with AML1/ETO to induce acute myeloid leukemia in mice. Proc Natl Acad Sci USA 100: 9506-9511, 2003.

8. Nishida S, Hosen N, Shirakata T, Kanato K, Yanagihara M, Nakatsuka S, Hoshida Y, Nakazawa T, Harada Y, Tatsumi N, et al: AML1-ETO rapidly induces acute myeloblastic leukemia in cooperation with the Wilms tumor gene, WT1. Blood 107: 3303-3312, 2006

9. Duncavage EJ and Tandon B: The utility of next-generation sequencing in diagnosis and monitoring of acute myeloid leukemia and myelodysplastic syndromes. Int J Lab Hematol 37 (Suppl 1): 115-121, 2015.

10. Dunlap J, Beadling C, Warrick A, Neff T, Fleming WH,Loriaux M, Heinrich MC, Kovacsovics T, Kelemen K, Leeborg N, et al: Multiplex high-throughput gene mutation analysis in acute myeloid leukemia. Hum Pathol 43: 2167-2176, 2012.

11. Cher CY, Leung GM, Au CH, Chan TL, Ma ES, Sim JP, Gill H, Lie AK, Liang R, Wong KF, et al: Next-generation sequencing with a myeloid gene panel in core-binding factor AML showed KIT activation loop and TET2 mutations predictive of outcome. Blood Cancer J 6: e442, 2016.

12. Yin CX, Wu FQ, Cao R, Jiang XJ, Yu GP, He H and Meng FY: Preliminary application of Ion Torrent $\mathrm{PGM}^{\mathrm{TM}}$ sequencing technology in the diagnosis of acute myeloid leukemia. Chin J Clin Lab Sci 33: 333-336, 2015 (In Chinese).

13. Yu G, Yin C, Jiang L, Zheng Z, Wang Z, Wang C, Zhou H, Jiang X, Liu Q and Meng F: Amyloid precursor protein cooperates with c-KIT mutation/overexpression to regulate cell apoptosis in AML1-ETO-positive leukemia via the PI3K/AKT signaling pathway. Oncol Rep 36: 1626-1632, 2016.

14. Yu G, Yin C, Jiang L, Xu D, Zheng Z, Wang Z, Wang C, Zhou H, Jiang X, Liu Q and Meng F: Amyloid precursor protein has clinical and prognostic significance in AML1-ETO-positive acute myeloid leukemia. Oncol Lett 15: 917-925, 2018.

15. Zhu HH, Zhang XH, Qin YZ, Liu DH, Jiang H, Chen H, Jiang Q, $\mathrm{Xu} \mathrm{LP}, \mathrm{Lu} \mathrm{J}, \mathrm{Han} \mathrm{W}$, et al: MRD-directed risk stratification treatment may improve outcomes of $t(8 ; 21)$ AML in the first complete remission: Results from the AML05 multicenter trial. Blood 121: 4056-4062, 2013.

16. Yuan Y, Zhou L, Miyamoto T, Iwasaki H, Harakawa N, Hetherington CJ, Burel SA, Lagasse E, Weissman IL, Akashi K, et al: AML1-ETO expression is directly involved in the development of acute myeloid leukemia in the presence of additional mutations. Proc Natl Acad Sci USA 98: 10398-10403, 2001.

17. de Guzman CG, Warren AJ, Zhang Z, Gartland L, Erickson P Drabkin H, Hiebert SW and Klug CA: Hematopoietic stem cell expansion and distinct myeloid developmental abnormalities in a murine model of the AML1-ETO translocation. Mol Cell Biol 22: 5506-5517, 2002. 
18. Conway O'Brien E, Prideaux S and Chevassut T: The epigenetic landscape of acute myeloid leukemia. Adv Hematol 2014: 103175, 2014.

19. Duployez N, Marceau-Renaut A, Boissel N, Petit A, Bucci M, Geffroy S, Lapillonne H, Renneville A, Ragu C, Figeac M, et al: Comprehensive mutational profiling of core binding factor acute myeloid leukemia. Blood 127: 2451-2459, 2016.

20. Qin YZ, Zhu HH, Jiang Q, Jiang H, Zhang LP, Xu LP, Wang Y, Liu YR, Lai YY, Shi HX, et al: Prevalence and prognostic significance of c-KIT mutations in core binding factor acute myeloid leukemia: A comprehensive large-scale study from a single Chinese center. Leuk Res 38: 1435-1440, 2014.

21. Schnittger S, Kohl TM, Haferlach T, Kern W, Hiddemann W, Spiekermann K and Schoch C: KIT-D816 mutations in AML1-ETO-positive AML are associated with impaired event-free and overall survival. Blood 107: 1791-1799, 2006.

22. Micol JB, Duployez N, Boissel N, Petit A, Geffroy S, Nibourel O, Lacombe C, Lapillonne H, Etancelin P, Figeac M, et al: Frequent ASXL2 mutations in acute myeloid leukemia patients with $\mathrm{t}(8 ; 21) /$ RUNX1-RUNX1T1 chromosomal translocations. Blood 124: 1445-1449, 2014.

23. Zenali M, deKay J, Liu Z, Hamilton S, Zuo Z, Lu X, Bakkar R, Mills $G$ and Broaddus R: Retrospective review of MET gene mutations. Oncoscience 2: 533-541, 2015.

24. Johnson J, Ascierto ML, Mittal S, Newsome D, Kang L, Briggs M, Tanner K, Marincola FM, Berens ME, Vande Woude GF and Xie Q: Genomic profiling of a hepatocyte growth factor-dependent signature for MET-targeted therapy in glioblastoma. J Trans Med 13: 306, 2015.

25. Park WS, Dong SM, Kim SY, Na EY, Shin MS, Pi JH, Kim BJ, Bae JH, Hong YK, Lee KS, et al: Somatic mutations in the kinase domain of the Met/hepatocyte growth factor receptor gene in childhood hepatocellular carcinomas. Cancer Res 59: 307-310, 1999.

26. Graeber TG and Eisenberg D: Bioinformatic identification of potential autocrine signaling loops in cancers from gene expression profiles. Nat Genet 29: 295-300, 2001.
27. Zheng R, Klang K, Gorin NC and Small D: Lack of KIT or FMS internal tandem duplications but co-expression with ligands in AML. Leuk Res 28: 121-126, 2004.

28. McGee SF, Kornblau SM, Qiu Y, Look AT, Zhang N, Yoo SY, Coombes KR and Kentsis A: Biological properties of ligand-dependent activation of the MET receptor kinase in acute myeloid leukemia. Leukemia 29: 1218-1221, 2015.

29. Soussi T, Legros Y, Lubin R, Ory K and Schlichtholz B: Multifactorial analysis of p53 alteration in human cancer: A review. Int J Cancer 57: 1-9, 1994.

30. Stengel A, Kern W, Haferlach T, Meggendorfer M, Fasan A and Haferlach C: The impact of TP53 mutations and TP53 deletions on survival varies between AML, ALL, MDS and CLL: An analysis of 3307 cases. Leukemia 31: 705-711, 2017.

31. Hou HA, Chou WC, Kuo YY, Liu CY, Lin LI, Tseng MH, Chiang YC, Liu MC, Liu CW, Tang JL, et al: TP53 mutations in de novo acute myeloid leukemia patients: Longitudinal follow-ups show the mutation is stable during disease evolution. Blood Cancer J 5: e331, 2015.

32. Wattel E, Preudhomme C, Hecquet B, Vanrumbeke M, Quesnel B, Dervite I, Morel P and Fenaux P: p53 mutations are associated with resistance to chemotherapy and short survival in hematologic malignancies. Blood 84: 3148-3157, 1994.

33. Li J, Yang L, Gaur S, Zhang K, Wu X, Yuan YC, Li H, Hu S, Weng Y and Yen Y: Mutants TP53 p.R273H and p.R273C but not p.R273G enhance cancer cell malignancy. Hum Mutat 35: 575-584, 2014.

34. Krejci O, Wunderlich M, Geiger H, Chou FS, Schleimer D, Jansen M, Andreassen PR and Mulloy JC: p53 signaling in response to increased DNA damage sensitizes AML1-ETO cells to stress-induced death. Blood 111: 2190-2199, 2008.

(i)(9) This work is licensed under a Creative Commons Attribution-NonCommercial-NoDerivatives 4.0 International (CC BY-NC-ND 4.0) License. 